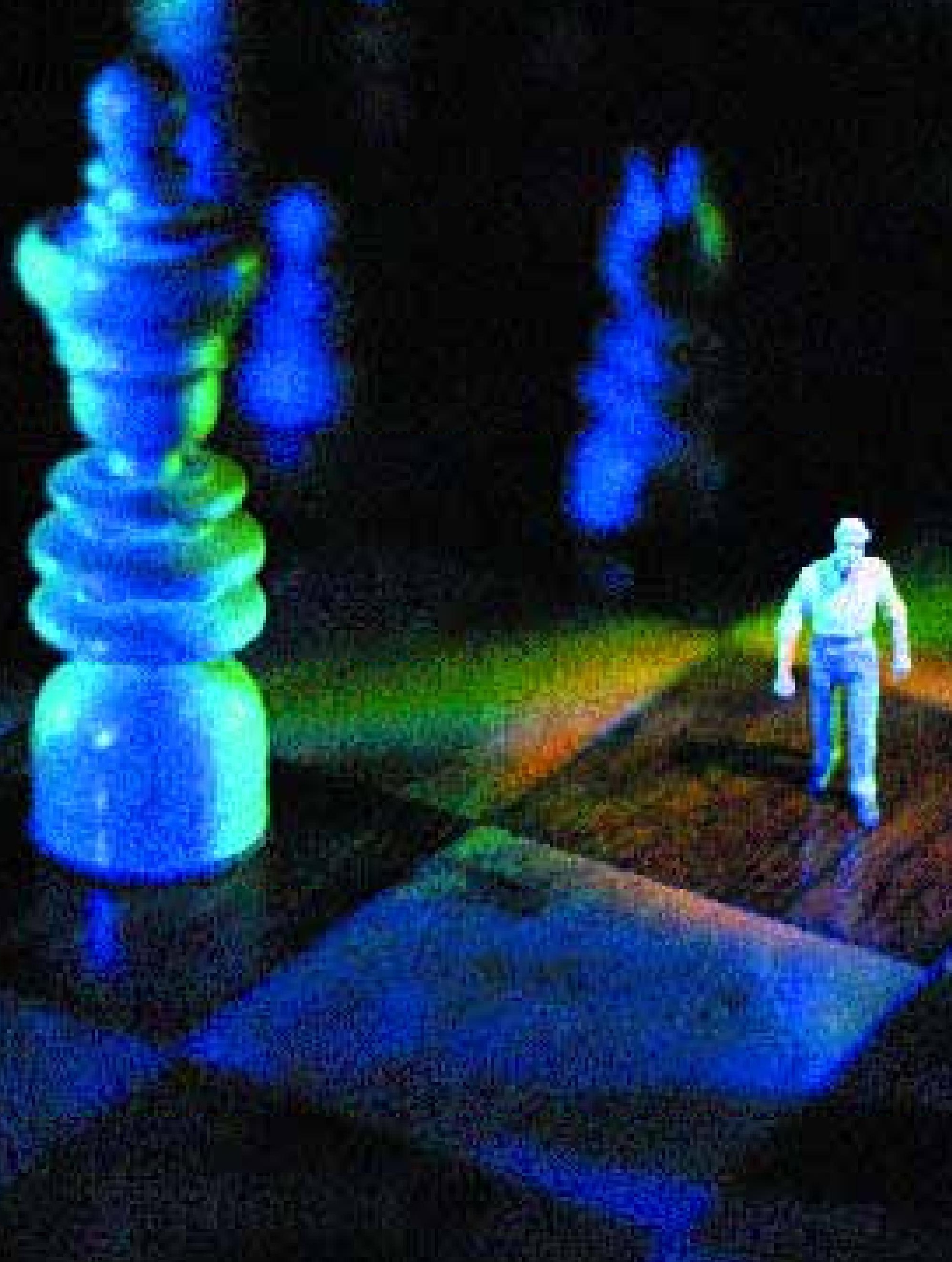


FINANÇAS

\section{Razão insuficiente}

esde o surgimento da psicanálise, sabe-se que o
comportamento humano é largamente influenciado por
emoções inconscientes. Por que então os adeptos da Teoria do Mercado Eficiente (TME) continuam a defender que o investidor é um ser perfeitamente racional? Há evidências da realidade do mercado de que essa hipótese é uma simplificação exagerada? Com a palavra, os estudiosos das Finanças Comportamentais.

por Mauro Halfeld UFPR e Fábio de Freitas Leitão Torres Booz Allen Hamilton

Hoje, o estudo das Finanças Comportamentais é um dos ramos mais polêmicos das Finanças. Reforçada pela turbulência do mercado financeiro internacional, a discussão em torno do assunto retrata o confronto entre os defensores de um modelo econômico e financeiro forte, porém desgastado pelo tempo, e os que propõem mudanças substanciais no Modelo Moderno de Finanças. As alterações pelas quais lutam os participantes do segundo grupo são significativas, uma vez que dizem respeito à definição da peça mais importante do "tabuleiro" das finanças: o investidor.

O surgimento das Finanças Comportamentais remete ao final da década de 1970, com a publicação dos trabalhos de dois psicólogos norte-americanos, Daniel Kahneman e Amos Tverski, sobre o comportamento e o processo de tomada de decisão do ser humano em situações de risco. No entanto, o crescimento explosivo do mercado financei- 
ro na década de 1980 e a capacidade do Modelo Moderno de Finanças para a análise de tal fenômeno acabaram por limitar o desenvolvimento das Finanças Comportamentais.

No final da década de 1980 e no começo da de 1990, porém, o Modelo Moderno de Finanças começou a apresentar sinais de desgaste. A crise do mercado financeiro em 1987, a constatação, cada vez mais freqüente, de anomalias não explicadas pelo modelo e a decadência da cultura yuppie contribuíram para tal desgaste. Nesse cenário, o estudo das Finanças Comportamentais, antes menosprezado no meio acadêmico, fortaleceu-se e ganhou adeptos.

\section{As Finanças Comportamentais não definem o agente do mercado como um ser totalmente racional, mas como um homem simplesmente normal.}

Em meados da década de 1990, ao contrário do que aconteceu nos anos 1980, a nova explosão do mercado só fez aumentar o interesse ao tema. A necessidade de encontrar explicações para comportamentos aparentemente injustificados valorizou os estudiosos que viam na irracionalidade humana um importante componente daquela conjuntura. A declaração de Alan Greenspan, do Federal Reserve, de que o que se observava na época era uma "exuberância irracional", foi o atestado que faltava para dar credibilidade àqueles que questionam conceitos importantes, entre os quais a eficiência do mercado e a racionalidade do investidor.

\section{Deficiências do Modelo Moderno de Finanças}

Um modelo, como se sabe, é uma tentativa de representação da realidade. Sendo essa realidade muito complexa, fazem-se hipóteses e aproximações com o intuito de simplificar tal representação sem que isso prejudique em demasiado sua fidelidade ao mundo real.

Segundo uma das hipóteses centrais do Modelo Moderno de Finanças, o homem ("homo economicus") é um ser perfeitamente racional que, no processo de tomada de decisão, é capaz de analisar todas as informações disponí- veis e considerar todas as alternativas para a solução de um problema. Tal hipótese contradiz os resultados de estudos realizados por psicólogos e psicanalistas, segundo os quais a racionalidade não é o centro nem a diretriz do pensamento e do comportamento humanos.

O homem das Finanças Comportamentais não é totalmente racional, é um homem simplesmente normal. Essa normalidade implica um homem que age, freqüentemente, de maneira irracional, que tem suas decisões influenciadas por emoções e por erros cognitivos - falhas na recepção e interpretação das informações. As decisões tomadas nessas circunstâncias seguem, em alguns casos, um padrão identificável, que pode e deve ser contemplado por um modelo econômico e financeiro.

O campo de estudos das Finanças Comportamentais é justamente a identificação de como as emoções e os erros cognitivos podem influenciar o processo de decisão de investidores e como esses padrões de comportamento determinam fenômenos de mercado. O grande desafio para os pesquisadores do tema está em provar que tais "anomalias" de comportamento são previsíveis e podem modificar o mercado de forma definida.

Aversão à perda. $O$ principal conceito utilizado pelas Finanças Comportamentais é a aversão à perda. Proposta pela primeira vez por Daniel Kahneman e Amos Tverski em 1979, essa idéia baseia-se na constatação de que as pessoas sentem muito mais a dor da perda do que o prazer obtido com um ganho equivalente. Essa tese contraria o preceito microeconômico conhecido como Teoria da Utilidade, segundo o qual o investidor avalia o risco de um investimento simplesmente de acordo com a alteração que ele pode proporcionar em seu nível de riqueza. O "homem normal" das Finanças Comportamentais, de outra forma, avalia o risco de um investimento com base em um ponto específico de referência a partir do qual mede ganhos e perdas.

Em alguns momentos, a aversão à perda pode ser confundida com a aversão ao risco. Na verdade, porém, o sentimento de aversão à perda é tão forte que supera a aversão ao risco. Essa idéia é representada em um dos estudos realizados por Kahneman e Tverski, apresentado a seguir:

A um grupo de pessoas foi apresentado o seguinte problema: 
- Além de tudo o que possui, você recebeu \$ 1 mil. Você deve, então, investir essa quantia, escolhendo entre:

a) um ganho certo de $\$ 500$;

b) uma chance de $50 \%$ de ganhar mais $\$ 1$ mil e $50 \%$ de chance de não ganhar nada.

A outro grupo foi apresentado outro problema:

- Além de tudo o que possui, você recebeu \$2 mil. Você deve, então, investir essa quantia, escolhendo entre:

a) uma perda certa de $\$ 500$;

b) uma chance de $50 \%$ de perder $\$ 1$ mil e $50 \%$ de chance de não perder nada.

No primeiro grupo, $84 \%$ dos integrantes escolheram a resposta "a"; no segundo grupo, 69\% dos integrantes escolheram a "b". Os dois problemas são idênticos no que diz respeito à variação total do nível de riqueza, porém a maneira como eles são formulados gera a discrepância entre os dois resultados. O exemplo acima revela que, diante de duas opções de ganhos, as pessoas tendem a escolher a opção mais conservadora. O mesmo não acontece diante da possibilidade de perder. Nessas situações as pessoas assumem riscos somente pela chance de não realizar a perda. Isso demonstra que o sentimento de aversão à perda é tão forte que se sobrepõe à aversão ao risco.

Existe, ainda, uma outra característica do comportamento humano, relacionada à aversão à perda, que é trabalhada pelos estudiosos das Finanças Comportamentais: o medo do arrependimento. Trata-se da constatação de que é muito doloroso para os investidores assumirem seus erros, fazendo com que eles tenham um comportamento que não proporciona o maior lucro possível em uma operação somente para evitar ter de divulgar uma perda - o que, novamente, contradiz a Teoria da Utilidade.

O Professor Meir Statman, da Universidade de Santa Clara, dá o exemplo de indivíduos que evitam vender papéis por um preço inferior ao de compra. Mantendo-os em sua carteira de investimentos por longos intervalos de tempo, acabam por comprometer sua liquidez conscientemente, deixando de realizar melhores opções de negócios nesse período devido ao medo do arrependimento. A vergonha de informar que realizaram um mal investimento faz com que alguns investidores façam opção somente por ações de grandes empresas com um bom histórico de retornos ou assumam posições sempre com a maioria do mercado. Afinal de contas, é mais fácil assumir um erro quando ele foi cometido pela maioria.

Autoconfiança excessiva. A autoconfiança excessiva é uma característica de comportamento presente na grande maioria da população mundial. Diversos estudos comprovam que cerca de $80 \%$ das pessoas consideram-se acima da média no que diz respeito às suas habilidades como motoristas, ao senso de humor, ao relacionamento com outras pessoas e à capacidade de liderança. No caso dos investidores, a maioria considera sua habilidade de vencer o mercado como acima da média. Na prática, no entanto, essa habilidade é muito difícil de ser encontrada.

Além de confiar demais em suas habilidades, os investidores acreditam que suas informações são melhores e mais confiáveis que as dos outros, o que é muito perigoso. Em uma negociação de compra e venda, as duas partes envolvidas possuem informações diferentes e, confiando nelas, assumem posições contrárias, mas, obviamente, os dois lados não podem estar inteiramente com a razão. Essa contradição, segundo Terrance Odean, Professor da Universidade da Califórnia em Davis, deveria fazer com que os investidores realizassem somente negociações nas quais tivessem segurança na obtenção de bons resultados. Mas a confiança exagerada em suas habilidades e informações faz com que eles tenham a tendência a realizar um volume excessivo de negócios.

\section{Exageros quanto ao otimismo e ao pessimis-}

mo. O otimismo a longo prazo é um reflexo da constância com a qual os investidores exageram sua expectativa de retorno futuro com base em resultados passados. Eles tendem a comprar papéis em evidência pelo fato de estarem em moda, estimando para o futuro os mesmos níveis de retorno anteriormente obtidos, o que nem sempre é verdade. Diante de uma série de retornos positivos, acreditam que estes continuarão a se repetir indefinidamente. Mesmo quando a sequência de bons resultados é interrompida, isso é encarado apenas como um "acidente de percurso". Tal comportamento, de comprar papéis já valorizados, fere o mais importante princípio do mercado financeiro: "comprar na baixa e vender na alta”. O que vem sendo observado é que investidores 
que compram um papel após um período de alta tendem a vendê-lo rapidamente, assim que obtêm algum lucro na operação, não otimizando seu retorno.

Isso pode ser explicado pela tendência humana em interpretar as novas informações de acordo com moldes preexistentes, em vez de analisá-las levando em conta as diferenças entre os momentos históricos. Obviamente, a força, a importância e a confiabilidade de uma nova informação para suplantar todo o conjunto de informações anteriores devem ser enormes. Esse comportamento não é inteiramente errado, o investidor não pode se deixar levar por todos os boatos e especulações que aparecem no mercado em profusão, mas também não pode ignorar ou deixar de analisar uma nova informação, contrastante com as anteriores, simplesmente pelo fato de ser aparentemente contraditória.

Reação exagerada às novidades do mercado. $\mathrm{O}$ preço de um papel negociado no mercado é ajustado de acordo com o que o próprio mercado acha que seja justo que se pague por ele. O método de avaliação resume-se, em linhas gerais, ao fluxo de caixa da empresa emissora da ação trazido ao valor presente. Dessa maneira, os preços desses papéis deveriam variar de acordo com a própria variação dos dividendos, descontados por uma taxa que representasse o custo de oportunidade de tal investimento. Entretanto, a observação do comportamento dos papéis negociados no mercado tem revelado que essa correlação entre a variação dos dividendos e o preço dos papéis não ocorre perfeitamente.

É muito difícil, se não impossível, prever e analisar todas as variáveis envolvidas na formação do preço dos papéis negociados. Porém, após o final do exercício, ajustar esse preço de acordo com os dividendos pagos, a inflação e os juros no período é uma tarefa muito mais simples. A esse preço posteriormente ajustado dá-se o nome de perfect foresight price e, ao compará-lo com o preço pelo qual esses papéis foram negociados no mercado, o resultado obtido costuma surpreender.

Como se nota na Figura 1, a volatilidade do preço dos papéis no mercado é muito maior que a variação real de seu valor. A constatação de que o mercado reage de maneira exagerada, e que, conseqüentemente, o preço de mercado não reflete exatamente a realidade, fere a Hipótese do Mercado Eficiente, outro fundamento do Modelo Moderno de Finanças.
Tal hipótese supõe que, após anos de negociação, o mercado chegou a um ponto em que o preço dos papéis nele negociados reflete tudo o que é conhecido e relevante sobre as empresas relacionadas a esses papéis. $\mathrm{O}$ único tipo de informação que os preços não refletiriam é a informação que ainda não é conhecida e nem pode ser prevista e, dessa maneira, as variações do mercado seriam completamente imprevisíveis, não seguindo qualquer padrão identificável. Em conseqüência disso, a eficiência do mercado acarretaria uma volatilidade muito menor do que a que de fato acontece.

\section{O mercado financeiro brasileiro. Ao contrário do} que acontece nos Estados Unidos, a polêmica em torno das Finanças Comportamentais no Brasil ainda é recente. Mas, evidentemente, os efeitos da irracionalidade do ser humano também são sentidos no mercado brasileiro.

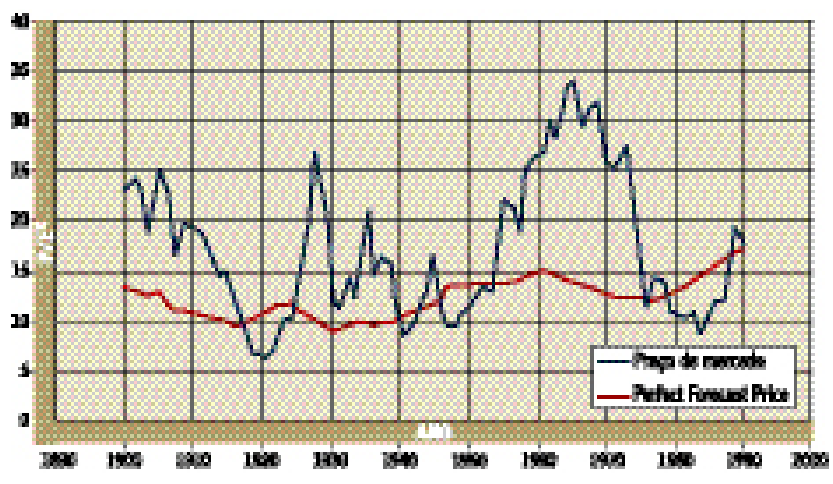

Figura 1 - Preço de mercado e perfect forecast price: taxas de desconto constantes Fonte: HAUGEN, R. A. Beast on Wall Street: how stock volatility devours our wealth. Upper Saddle River : Prentice Hall, 1999.

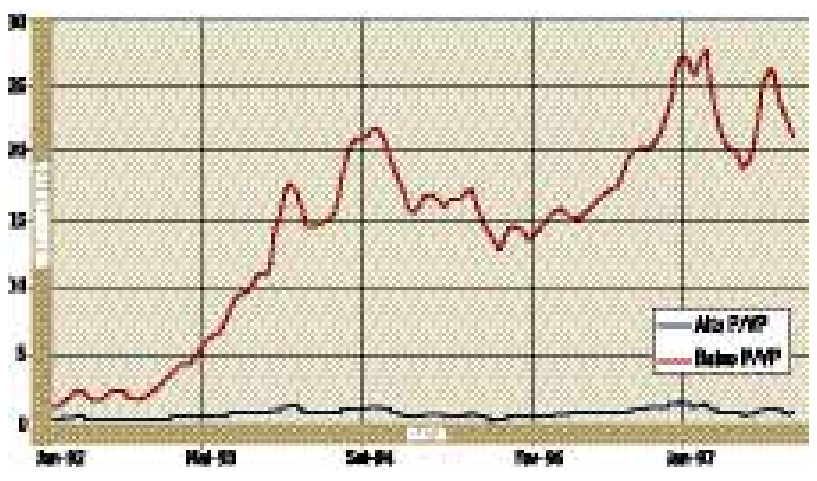

Figura 2 - Rendimentos acumulados no período de janeiro de 1992 a junho de 1998 
Uma análise comparativa de desempenho envolvendo as ações mais valorizadas e as menos valorizadas do mercado brasileiro mostra resultados similares a que chegaram outros pesquisadores com relação a outros mercados: as ações menos valorizadas (baixo preço/valor patrimonial) têm, em média, um desempenho melhor que as ações mais valorizadas (alto preço/valor patrimonial).

Como se verifica na Figura 2, o melhor desempenho médio da carteira fictícia composta pelos papéis menos valorizados comprova empiricamente que as ações em queda são as que apresentam maior probabilidade de subir num futuro próximo. Esse desempenho, porém, é acompanhado de uma volatilidade muito grande quando comparada com a da composta pelos papéis mais valorizados, indicando, também, uma possível reação exagerada do mercado.

O Professor Newton da Costa Jr., da Universidade Federal de Santa Catarina, em um de seus diversos estudos sobre o mercado financeiro brasileiro, analisou a ocorrência de reação exagerada dos investidores com base no desempenho mensal de duas carteiras de investimento teóricas que ele define como "perdedora" e "vencedora", ambas formadas por ações negociadas na Bolsa de Valores de São Paulo (Bovespa) no período de 1970 a 1989. A carteira "perdedora" seria composta, em um mês, pelas ações que tiveram o pior desempenho no mês anterior; a carteira "vencedora", por sua vez, seria composta pelas ações que tiveram o melhor desempenho no mês anterior. Tais carteiras são renovadas, mês a mês, de acordo com o comportamento desses papéis no mercado. Os resultados obtidos apontam que não só o efeito da reação exagerada é sentido no mercado brasileiro, mas também sua magnitude é maior que a observada no mercado norte-americano.

Perspectivas. As Finanças Comportamentais, em seu atual estágio de desenvolvimento, não têm a força e a aceitação necessárias para derrubar o Modelo Moderno de Finanças. Existem alguns conceitos que precisam ser mais bem definidos e algumas incoerências a serem resolvidas. Além disso, falta à teoria, principalmente, um modelo matemático confiável e abrangente. Muitos estudiosos têmse atido a desenvolver as idéias que lhes fornecem embasa- mento conceitual, sem dar muita importância aos conceitos matemáticos e estatísticos que o compõem.

Os modelos matemáticos apresentados até agora com o intuito de explicar anomalias apontadas pelas Finanças Comportamentais são muito específicos, tratando apenas de um fenômeno e falhando na tentativa de explicar outros. Essa deficiência, no entanto, tem feito com que alguns pesquisadores concentrem suas pesquisas nas formulações matemáticas que confirmariam as idéias dos principais estudiosos do assunto, mudando um pouco o cenário de pesquisa atual em comparação com alguns anos atrás.

Eugene Fama, da Universidade de Chicago, um dos maiores defensores da Hipótese do Mercado Eficiente, concorda que existem anomalias no Modelo Moderno de Finanças, entretanto, como elas aconteceriam de forma aleatória, acabariam por se compensar e seriam, portanto, consistentes com a eficiência de mercado. $O$ fato de não se conseguir rejeitar estatisticamente a Hipótese do Mercado Eficiente é, com certeza, um dos pontos fracos das Finanças Comportamentais e um dos focos de trabalho de seus defensores.

Há os que defendem uma formulação mais moderada capaz de conciliar essas duas teorias aparentemente

\section{Para os investidores, é mais fácil assumir um erro quando ele foi cometido pela maioria.}

contrastantes. Desse ponto de vista, as Finanças Comportamentais são vistas não como um adversário, mas sim como um aperfeiçoamento do Modelo Moderno de Finanças. Os sofisticados modelos matemáticos atuais não seriam inúteis, apenas requereriam um aperfeiçoamento que incorporasse as descobertas de estudos sobre a irracionalidade do investidor. O debate em torno do valor das Finanças Comportamentais ainda está longe do fim. A polêmica cresce dia após dia, tornando aconselhável especial atenção ao tema, pois, se seus adeptos estiverem certos, mudanças substanciais no mundo das finanças estão por vir. 